\title{
İnsansız Su Altı Araçlarında Kullanılan İtici Motorların İtki Kuvveti Hesaplanmasında Uygulanan Analiz Yöntemlerinin Karşılaştırılması
}

\author{
Talha Gülgün ${ }^{*}$, İsmail Yalçınkaya ${ }^{2}$, Mertcan Erdoğdu $^{3}$, Akif Durdu ${ }^{4}$

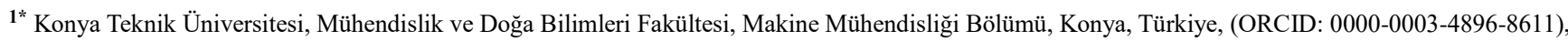 \\ talhagulgunn@gmail.com \\ ${ }^{2}$ Konya Teknik Üniversitesi, Mühendislik ve Doğa Bilimleri Fakültesi, Makine Mühendisliği Bölümü, Konya, Türkiye (ORCID: 0000-0002-6567-399X), \\ ismailyalcinkaya96@gmail.com \\ ${ }^{3}$ Konya Teknik Üniversitesi, Mühendislik ve Doğa Bilimleri Fakültesi, Makine Mühendisliği Bölümü, Konya, Türkiye (ORCID: 0000-0003-4613-8729), \\ mrtcn7899@gmail.com \\ ${ }^{4}$ Konya Teknik Üniversitesi, Mühendislik ve Doğa Bilimleri Fakültesi, Elektrik Elektronik Mühendisliği Bölümü, Konya, Türkiye, (ORCID: 0000-0002-5611-2322), \\ adurdu@ktun.edu.tr
}

(İlk Geliş Tarihi 13 Ekim 2021 ve Kabul Tarihi 27 Aralık 2021)

(DOI: 10.31590/ejosat.1008881)

ATIF/REFERENCE: : Gülgün, T., Yalçınkaya, İ., Erdoğdu, M. \& Durdu, A. (2021). İnsansız Su Altı Araçlarında Kullanılan İtici Motorların İtki Kuvveti Hesaplanmasında Uygulanan Analiz Yöntemlerinin Karşılaştırılması. Avrupa Bilim ve Teknoloji Dergisi, (31), 791-795.

$\ddot{O} \mathbf{z}$

Su altı araçları pek çok uygulama alanında aktif bir şekilde kullanılmaktadır. Uzaktan kontrol edilebilen insansız su altı araçlarının yanı sıra otonom bir şekilde çalışma kapasitesine sahip araçlarda bulunmaktadır. İnsansız su altı araçları; arama - kurtarma, su altı keşif ve gözlem, askeri amaçlı uygulamalar gibi alanlarda görev almaktadır. Su altı araçlarında bulunan başlıca kısımlar ise iskelet gövde, itici motorlar, sızdırmalığı sağlanmış bölme, batarya veya güç kaynağıdır. İtici motorlar aracın hareket kabiliyetini doğrudan etkileyerek önemli parametrelere yön verir. İtici motor dizilimleri sonucu serbestlik derecesi değişebilirken, itki kuvveti, aracın ulaşabileceği maksimum hız gibi parametrelerde de belirleyici rol oynar. Bu çalışmada; su altı araçlarında kullanılan itici motorların bilgisayar destekli analiz programında itki kuvveti hesabında kullanılabilecek iki yöntem üzerinde durulmuştur. İki durum birbirinden bağımsız bir biçimde analiz edilmiş, oluşan itki kuvveti değerleri hesaplatılmıştır. Hesaplamalı akışkanlar dinamiği analizleri sonucu oluşan iki durumdaki itki kuvveti değerleri birbirleri ile karşılaştırılmıştır. Her iki yöntem sonucunun da \%1'den az bir fark ile neredeyse aynı sonuçları verdiği görülmüştür. Çalışma sırasında kullanılan itici motorların pervane ve nozzle kısımları özgün tasarım olup 3D yazıcıdan üretilmiştir. Üretimi tamamlanan iticiler, çalışmalarda kullanılması için tasarlanan su altı aracına entegre edilmiştir. Yapılan çalışma sonucu itici motorlada oluşan itki kuvvetinin hesabında iki yönteminde kullanılabileceği, hangi yöntem kullanılmış olursa olsun bulunan değerin diğer yöntem ile hesaplanacak olan değere çok yakın veya aynı olacağına ulaşılmıştır.

Anahtar Kelimeler: Hesaplamalı Akışkanlar Dinamiği Analizleri, Hesaplama Yöntemi, İnsansız Su Altı Aracı, İtici Motor, İtki Kuvveti.

\section{Comparison of the Analysis Methods Applied in Calculating the Thrust Force of the Thrusters Used in Unmanned Underwater Vehicles}

\begin{abstract}
Underwater vehicles are actively used in many application areas. It is available in unmanned underwater vehicles that can be controlled remotely, as well as vehicles capable of operating autonomously. Unmanned underwater vehicles; It is involved in areas such as search and rescue, underwater reconnaissance and observation, military applications. The main parts found in underwater vehicles are the frame body, thrusters, sealed compartment, battery, or power source. Thrusters directly affect the mobility of the vehicle and give direction to important parameters. While the degree of freedom may vary as a result of thrust arrays, the thrust force also plays a decisive role in parameters such as the maximum speed that the vehicle can reach. In this study, two methods that can be used in the calculation of thrust force in the computer-aided analysis program of thrusters used in underwater vehicles are
\end{abstract}

*Sorumlu Yazar: talhagulgunn@gmail.com 
emphasized. The two situations were analyzed independently of each other and the resulting thrust force values were calculated. The thrust force values in the two cases, which were formed as a result of computational fluid dynamics analysis, were compared with each other. It was found that the results of both methods gave almost the same results with a difference of less than $1 \%$. The propeller and nozzle parts of the thrusters used during the study are original designs and produced from a 3D printer. The thrusters, whose production has been completed, are integrated into the underwater vehicle designed for use in studies. As a result of the study, it was found that the thrust force generated in the thrusters can be used in two methods of calculation, regardless of which method is used, the value found will be very close or the same as the value to be calculated by the other method.

Keywords: Computational Fluid Dynamics Analysis, Computing Method, Thruster, Thrust Force, Unmanned Underwater Vehicle.

\section{Giriş}

İnsansız su altı araçları her geçen gün daha çok kullanılmakta ve önemi artmaktadır. İnsansız su altı araçları; Denizcilik faaliyetleri, arama kurtarma operasyonları, su altı incelemesi ve gözlemlenmesi, askeri operasyonlar ve faaliyetler, su altı bakım, onarım, kurulum, batıkların incelenmesi gibi pek çok kritik alanda sıklıkla kullanılmaya başlanmıştır (Boehm et al., 2018; Budiyono, 2009; Tangorra et al., 2007). İnsansız su altı araçları literatürde bir operator tarafindan uzaktan kontrol edilebilen (ROV, Remotely operated vehicle,) ve herhangi bir operator müdehalesine gerek kalmadan otonom bir biçimde faliyet gösterebilen (AUV, autonomous underwater vehicle,) su altı araçları olarak iki farklı biçimde sınıflandırılmıştır.

Kullanım alanı ve amacı doğrultusunda farklı boyutlarda ve ağırlıklarda tasarlanabilme imkanı sunan su altı araçları, üzerine yerleştirilecek çeşitli sensörler ve robot kollar sayesinde bir çok veriyi ve görevi de yerine getirebilirler (Budiyono, 2009; Ludvigsen et al., 2017; Negahdaripour et al., 2006). Aracin üzerine yerleştirilecek kameralar sayesinde dalgıçlar için girilmesi tehlikeli olan bölgelere rahatlıkla erişebilir, daha öncesinde görüntü alınmamış alanların keşfi gerçekleştirilebilir (Christ et al., 2013; Nian et al., 2013). Su altı araçları genel olarak uzaktan kontrol yöntemi ile kablolar vasıtasıyla bir operator tarafindan kullanılmaktadır. Yüksek hareket kabiliyetinin sağlanması için itici motorlar, elektronik bileşenlerin muhafazası için sızdırmazlığı sağlanmış bölme, güç kaynağı veya batarya ve araç üzerindeki bileşenlerin bir bütün şekilde durması amacıyla iskelete sahiptir. İskeletin bir başka görevi ise dış ortamdan gelebilecek darbelere karşı araç içerisindeki bileşenlerin korunmasıdır.

Araç üzerinde bulunan itici motorlar, aracın hareket kabiliyetine doğrudan etki ederek sebestlik derecesinin (DOF) belirlenmesini sağlar. Yüksek serbestlik derecesi, istenilen görevlerin daha rahat bir biçimde gerçekleştirilmesine olanak sağlar ve kullanan operatörün araca daha hakim olmasına neden olur.

Bu çalışmada; insansız su altı araçlarında kullanılan itici motorların sahip olduğu itki kuvveti değerinin hesaplanması için iki farklı yöntem üzerine çalışılmıştır. Bilgisayar destekli tasarım programında hesaplamalı akışkanlar dinamiği yöntemi ile itki kuvveti analizleri gerçekleştirilmiştir. Analiz türlerinden ilki, araç üzerinde bulunan ve ileri - geri hareketi sağlayan 4 adet itici motorun aynı anda modellenmesi sonucu elde edilen itki kuvvetinin hesaplanmasıdır. Diğer yöntemde ise araç üzerinde kullanılan itici motor, diğer motorlardan bağımsız bir biçimde tek başına modellenmiş ve itki kuvveti değeri hesaplatılmıştır. Elde edilen değer 4 ile çarpılarak, araçta ileri - geri hareketi için 4 adet itici motor kullanılmıştır, aracın ileri - geri hareketini sağlayan durum elde edilmiştir. Çıkan her iki farklı yöntemde de aracın ileri hareketi sırasında oluşan itki kuvveti değerleri karşılaştırılmıştır.

\section{Materyal ve Metot}

İnsansız su altı araçları küçük boyutlara sahip olması ve hafiflik gibi parametrelerden dolayı su altı görüntü alma, su atı antik kalıntıların incelenmesi gibi değişik konularda da sıklıkla kullanılmaktadır. Düşük maliyetli su altı araçlarının yanı sıra üzerlerinde kullanılan sensörlerin son teknoloji olmasından kaynaklı olarak yüksek maliyetli araçlar da üretilebilmektedir. Kullanıcı amacı ve doğrultusunda araçta bulunacak bileşenler özenle seçilir ve buna uygun araç tasarımına gidilirse maliyet düşürülebilmektedir. Araçtan alınan veriler eşliğinde bilimsel çalışmalar gerçekleştirilebilir, deniz canlıları incelenebilir, literature yeni keşifler sağlanabilmektedir.

\section{1. İtici Motor - Thruster}

İticiler su altı araçlarında bulunan en önemli kısımlardan biridir. Motorlar sayesinde su altı aracına hareket kabiliyeti kazandırılır (Chin et al., 2006; Healey et al., 1995). Temel olarak aracın ileri - geri, aşağı - yukarı hareketi sağlanırken farklı motor dizilim ve konfigürasyonları sayesinde ekstra serbestlik derecesi katacak manevra kabiliyetleri de araca tanınmış olur (Gülgün et al., 2020; Yoeger et al., 1990). Hareket kabiliyetinin yanı sıra dış ortamdan gelen müdehalelere karşı aracın dengesinin korunmasını sağlayarak görevlerin başarılı bir biçimde gerçekleştirilmesini sağlar (Muljowidodo et al., 2009).

İtici motorlar hareket kabiliyetini üzerlerinde bulundurdukları motor ve pervane sayesinde gerçekleştirir (Gülgün et al., 2020). Pervane ve rotor kısmı nozzle içerisine alınarak motor bileşenlerinin diş etmenlerden zarar görmesini engeller. Su altı araçlarında piyasada hazır olarak satılan itici motorlar kullanılabileceği gibi farklı malzemeler kullanılarak 3D yazıcılardan da pervane ve nozzle kısımları üretilebilmektedir.

İtici tasarımı gerçekleştirilirken su altı aracının kullanılacağı ortam, gerçekleştireceği operasyonel faliyet ve aracın bünyesinde barındırdıklarından dolayı sahip olacağı ağırlık gibi pek çok paramete göz önüne alınmalıdır (Muljowidodo et al., 2009). Belirlenen parametreler eşliğinde itici motorların 3 boyutlu tasarımı gerçekleştirilmeli, yapısal ve hesaplamalı akışkanlar dinamiği analizlerine tabi tutulmalıdır. Pervane ve nozzle yapısı için sonlu elemanlar analizleri çeşitlerinden olan statik analizler gerçekleştirilerek tasarımın dayanımı, modal analizler gerçekleştirilerek titreşimden kaynaklı oluşabilecek rezonans durumları ve bu durumlarda yapının sergileyeceği mukavemet özellikleri incelenebilir. Hesaplamalı akışkanlar dinamiği analizleri sayesinde aracın sahip olacağı itki kuvveti, hız, basınç, türbülans değerleri ve bu değerlerin dağılımı incelenebilmektedir. Tasarım aşamasında gerçekleştirilen bu tarz 
analizler sayesinde zamandan ve maliyetten tasarruf sağlanarak en kısa zamanda en verimli itici tasarımına ulaşmak mümkün olabilmektedir. Bilgisayar ortamında gerçekleştirilen analizler sonrası tasarım üretilerek test aşamasına geçilir. Testleri başarıyla tamamlayan itici motorlar, su altı araçlarında operasyonel faaliyetlerini gerçekleştirmek için hazır durumdadırlar.

Çalışma sırasında kullanılacak iticilerin pervane ve nozzle kısımları özgün olarak tasarlanmış ve yerli olarak üretilmiştir. Malzeme olarak PLA Flament kullanılmış, üretimi 3D yazıcı yardımıyla gerçekleştirilmiştir. Nozzle dış çapı $100 \mathrm{~mm}$, uzunluğu ise $67 \mathrm{~mm}$ 'dir. Pervane en büyük çap değeri 82, gövde kalınlığ 1 ise $10 \mathrm{~mm}$ 'dir. Üretim aşaması tamamlandıktan sonra montaj1 gerçekleştirilen iticilere ait görsel Şekil 1'de gösterilmiştir.

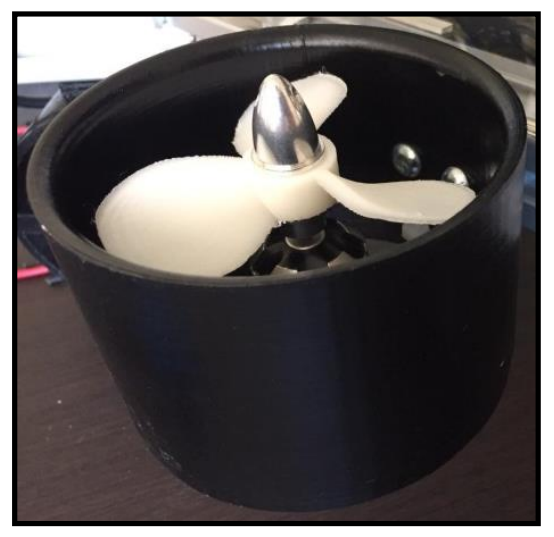

Şekil 1. Üretilen nozzle ve pervane

Çalışma için özgün olarak tasarlanıp üretilen ve test aşamalarında kullanlan su altı aracı Şekil 2'de gösterilmiştir.

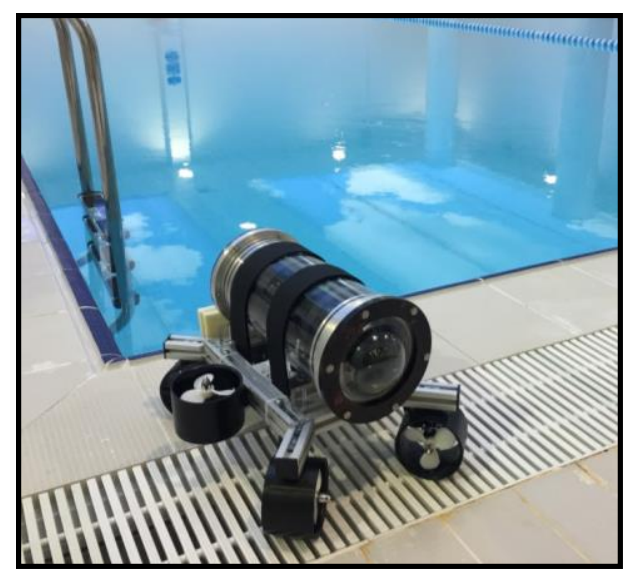

Şekil 2. Üretilen su altı aracı

\subsection{Hesaplamalı Akışkanlar Dinamiği Analizleri}

Günümüzde pek çok mühendislik dalında bilgisayar destekli tasarım programları kullanılmakta ve bu programlar vasıtasıyla birçok analiz, modelleme ve simülasyonlar ile desteklenerek gerçekleştirilmektedir (Amory et al., 2018). Teknolojinin her geçen gün daha da ileri bir seviyeye taşınmasıyla gerçekleştirilen analizler daha hızlı ve gerçeğe daha yakın sonuçlar elde edilerek sonuçlanabilmektedir.
İtici motorların tasarımı gerçekleştirildikten sonra hesaplamalı akışkanlar dinamiği analizlerine tabi tutulmuş, oluşacak itki kuvveeti değeri hesaplatılmıştır. İki farklı yaklaşım kullanılarak gerçekleştirilen analizler, hesaplatılan değerler bakımından birbirleriyle karşılaştırılmıştır.

\subsection{Analizin Modellenmesi ve Simülasyon}

Gerçek hayattaki durumların bilgisayar ortamında test edilebilmesi için durumun modellenmesi gerekmektedir. Yapılan analizler tasarlanan iticilerin sahip olacağı itki kuvvetinin 2 farklı analiz yöntemi kullanarak hesaplatılması ve karşılaştırılması üzerinedir.

Hesaplama alanının boyutları sisteme tanımlanarak modelleme işlemine başlangıç yapılır. Hesaplama alanı analiz sonucunda elde edilecek değerlerin doğruluğu için önem arz etmektedir. Hesaplama alanı su altı aracının testlerinin yapıldığ yüzme havuzu boyutları olan 10 × 5 × 2 metre olacak şekilde tanımlanmıştır ve araç havuzun tam ortasına konumlandırılmıştır.

İlk durumun modellenebilmesi için aracın ileri hareketini sağlayan 4 adet itici içerisindeki pervaneler sisteme entegre edilmiştir. Pervanelerin dönüş yönünü temsil etmek amacıyla pervane çapı ve kalınlığında silindirik bir disk oluşturulmuş ve pervane üzerine konumlandırılmıştır (bknız. Şekil 3-a). Sınır şartı olarak ise motorun rotor kısmı gerçek duvar ve stator olarak seçilmiştir (bknız. Şekil 3-b). Şekil 3'te gösterilen bu modelleme, kullanılan her iki yöntemde de ortaktır.

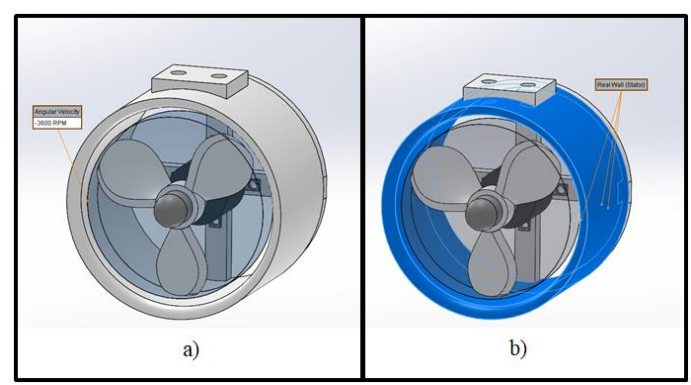

Şekil 3. Pervane sınır şartları ve silindirik disk

Akış analizlerinde pervanelerin açısal hızları, kullanılan motorun teknik bilgi formundan alınmış, 3600 RPM araç için planlanan en yüksek çalışma devri olarak belirlenmiş ve analizlerde giriş parametresi olarak kullanılmıştır. Aracın ileri hareketinin modellenebilmesi için; araç önündeki 2 iticinin pervanelerine 3600 rpm, arka kısımdaki 2 iticinin pervanelerine $3600 \mathrm{rpm}$ açısal hız tanımlanmıştır.

Diğer yöntem ile gerçekleştirilecek analiz için oluşturulan akış alanı $2 \mathrm{~m}$ x $2 \mathrm{~m}$ x $2 \mathrm{~m}$ ebatlarındadır ve itici bu alanın ortasına konumlandırılmıştır. Bu gibi dış akış analizlerinde, analize tabi tutulan nesnenin sahip olduğu boyutlar, belirli oranlarda büyültülerek hesaplama alanı için gerekli boyut değerleri elde edilir ve analizlin sonsuz bir ortamda yapıldığı tasvir edilmiş olur. 2 × 2 × 2 metrelik ebatlar kullanıldığında bu sonsuz ortamın tasvir edilmesi sağlandığı için analizin daha kısa sürede yakınsaması amacıyla ilk durumdaki hesaplama alanı boyutu tercih edilmemiştir. Pervanelerin dönüşünü simule etmek amacıyla silindirik disk oluşturulmuş ve $3600 \mathrm{rpm}$ açısal hız 
giriş parametresi olarak verilmiştir. İticinin rotor kısımları gerçek duvar ve stator olarak seçilmiştir.

\section{Araştırma Sonuçları ve Tartışma}

\subsection{Araştırma Sonuçları}

Hesaplamalı akışkanlar dinamiği yöntemi ile bilgisayar destekli tasarım programında gerçekleştirilen analizler sonucu kullanılan ilk yöntemde, belirlenen çalışma devrinde elde edilen toplam itki kuvveti 85,53 $\mathrm{N}$ (Newton) olarak hesaplanmış, bu $\mathrm{N}$ değeri 9,81' e bölünerek kgf (Kilogramforce) karşılığ1 bulunmuştur. Denkem 1'de gösterilmiştir.

$$
\begin{gathered}
\text { Toplam İtki }=\frac{85,53 \mathrm{~N}}{9,81} \\
\text { Toplam } \dot{\mathrm{I}} \mathrm{t} k i=8,71 \mathrm{Kg} f
\end{gathered}
$$

8,71 kgf'luk değer, aracın su altında 8,71 kg'lık bir ağırlığı zorlanmadan çekebileceği anlamına gelmektedir. Çalışma sürecinde üretilen ve testler sırasında kullanılan su altı aracı su içerisinde askıda kalır yapıda olduğu için bu itki kuvveti değeri planlanan görevler için yeterli seviyededir. Şekil 4'te iterasyon başına hesaplanan itki kuvveti grafiğe dönüştürülmüştür.

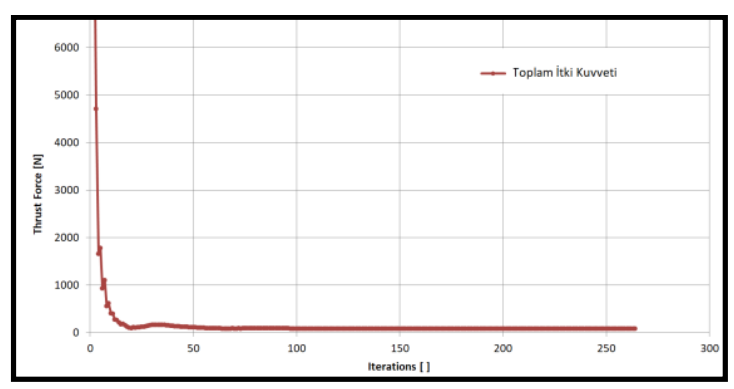

Şekil 4. Iterasyon başına hesaplanan itki kuvveti

Grafikte görüldüğü üzere oluşan kuvvetin başlarda yüksek değerlerden değişimler göstererek bir noktaya düşmüş ve daha sonrasında kararlı bir yapıya bürünerek yakınsadığı görülmektedir. Yakınsama, programın elde ettiği kuvvet değerinde karar kıldığı anlamını taşımaktadır. Şekil 5'te iticilerinin aktif olarak çalışması sırasında akışın görselleştirilmesi sonucu oluşan görseller ön, yan ve üst görünüş olarak sırasıyla gösterilmiştir. Oluşan hız değerleri belirli aralıklara göre renklendirilmiş olup hangi rengin hangi değere karşılık geldiği resimdeki skalada gösterilmiştir.

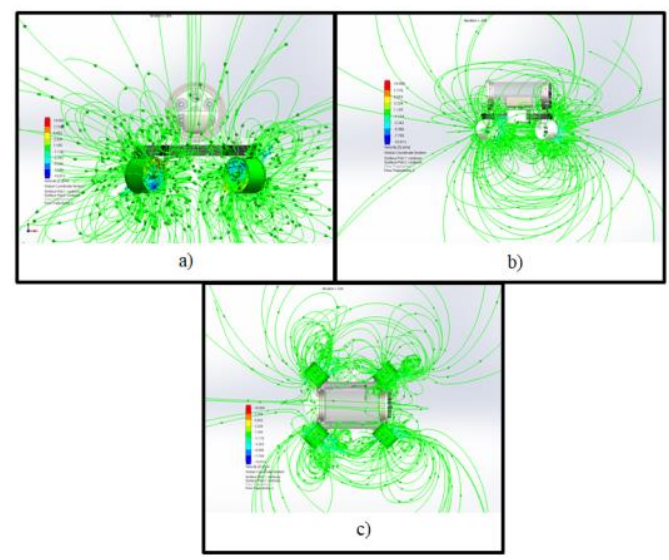

Şekil 5. Iticilerinin aktif olarak çalışması sırasında akışın görselleştirilmesi

Diğer yöntem kullanılarak gerçekleştirilen analiz sonucunda ise tek bir iticiden kaynaklı oluşan itki kuvveti 21,17 N olarak hesaplanmıştır ve Şekil 6'da itki kuvveti değerinin grafiğe dökülmüş hali gösterilmiştir.

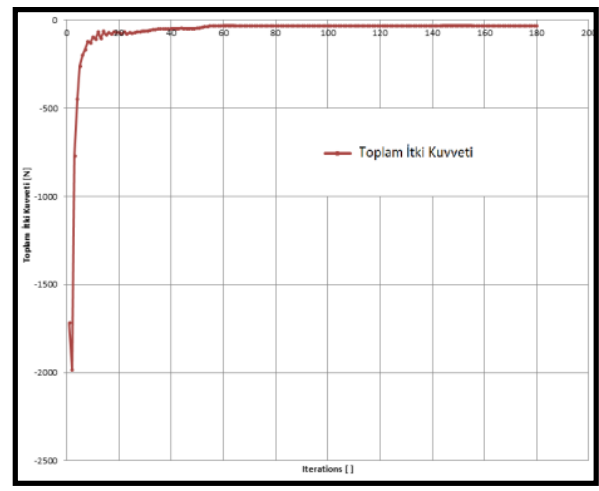

Şekil 6. Itki kuvveti sonucu

Grafikteki itki kuvveti değerlerinin negatif olması yönü temsil etmektedir ve hesaplamalar yapılırken sadece kuvvet değerleri üzerinden işlem yapılmıştır.

Dört adet itici motor aracın ileri hareketi için kullanıldığından dolayı bulunan bu değer 4 ile çarpılarak aracın ileri yönde sahip olacağı toplam itki kuvveti bulunmuştur. Denklem 2'de toplam itki kuvveti hesabı gösterilmiştir.

$$
\begin{gathered}
\text { Toplam İtki Kuvveti }=21,17 N \times 4 \\
\text { Toplam İtki Kuvveti }=84,68 N
\end{gathered}
$$

Denklem 3'te oluşan 84,68 N'luk itki kuvveti değeri Kgf cinsine dönüştürülmüştür.

$$
\begin{gathered}
\text { Toplam } \dot{\mathrm{I}} \mathrm{t} k i=\frac{84,68 \mathrm{~N}}{9,81} \\
\text { Toplam } \dot{\mathrm{I}} \mathrm{k} k i=8,63 \mathrm{Kgf}
\end{gathered}
$$

Denklem 3'te de görüldüğ̈̈ üzere toplam itki kuvveti 8,63 Kgf olarak hesaplanmştır. Şekil 7'de pervanelerin aktif olarak çalışması sırasında akışın görselleştirilmesi sonucu oluşan görsellere yer verilmiştir. Oluşan hız değerleri belirli aralıklara göre renklendirilmiş olup hangi rengin hangi değere karşıllk geldiği resimdeki skalada gösterilmiştir.

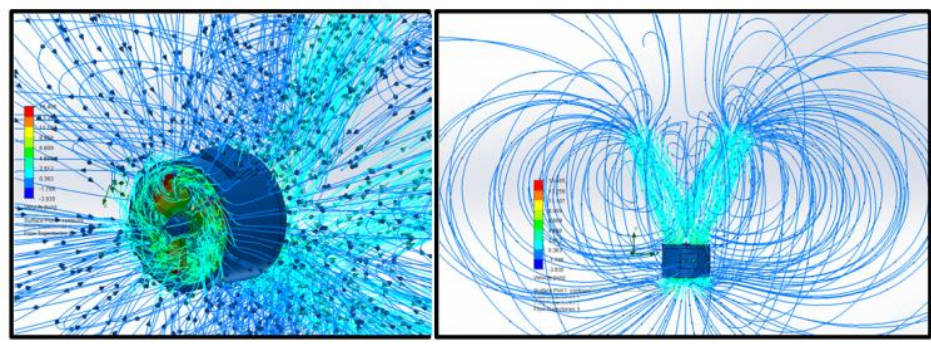

Şekil 7. Pervanelerin aktif olarak çalışması sırasında akışın görselleştirilmesi 
Şekilde görüldüğü üzere akış çizgilerinin düzenli bir biçimde tekrar eden hareketler izlemesi, çalışma için yapılan özgün pervane ve nozzle tasarımının uygun bir dizayna sahip olduğunu göstermektedir.

\subsection{Tartışma}

Gerçekleştirilen ilk yöntemde analiz sonucunda toplam itki kuvveti değeri 85,53 N gelirken, ikinci yönteme göre toplam itki kuvveti değeri 84,68 N gelmektedir. $\mathrm{Bu}$ iki değerin yüzdelik olarak ne kadar farklılık gösterdiği ise denklem 4'te hesaplanmıştır.

$$
\begin{gathered}
\% \text { Fark }=\frac{85,53-84,68}{85,53} \times 100 \\
\% \text { Fark }=0,9938
\end{gathered}
$$

Denklem 4 sonucundan da anlaşılacağı üzere her iki yöntemle yapılan analiz sonuçlarının birbirlerine \% 0,9938 gibi çok yakın değerlerde sonuçlandığı ve \%1'den düşük bir fark olduğu gözlemlenmiştir. Bu sonuç analizlerde kullanılan yöntemlerin ve analizlerin doğruluğunu kanıtlar niteliktedir.

$\mathrm{Bu}$ çalışmadan elde edilecek sonuçlar, mühendislik alanında bilime hizmet etmek isteyen mühendis ve mühendis adayları tarafindan kullanılabilme özelliğine sahiptir. $\mathrm{Su}$ altı sistemlerinde kullanılmak üzere tasarlanacak olan insanlı insansız su altı araçlarının, üzerlerinde bulunan iticilerden dolayı sahip olacağı itki kuvveti değeri hesabı için yol gösterici durumda bulunan bu araştırma, hangi yöntemlerin kullanılabileceği, kullanılan farklı yöntemlerin sonuçları değiştirip değiştirmeyeceği konusunda okuyucuya bilgi sahibi edinmesini sağlayacaktır.

\section{Sonuç}

$\mathrm{Bu}$ çalışmada su altı araçlarında kullanılan itici motorların sahip olduğu itki kuvvetinin hesaplanmasına kullanılan iki farkı yöntem ele alınmıştır. Hesaplamalı akışkanlar yöntemi ile bilgisayar ortamında gerçekleştirilen analizler sonucu iki farklı yöntemle hesaplatılan itki kuvveti değerleri karşılaştırılmıştır. İki durum arasında oluşan kuvvet değeri fark1 \%1'den az olarak hesaplanmıştır. Elde edilen bu değerler itici motorların itki kuvveti hesabında gerçekleştirilen her iki yönteminde kullanılabileceği, herhangi birisinin kullanılması durumunda ise bir sakınca olmadığını ortaya koymuştur.

\section{Teşekkür}

$\mathrm{Bu}$ çalışmanın yürütülmesi sırasında yardımlarını esirgemeyen Sayın Konya Teknik Üniversitesi Rektörü Prof. Dr. Babür Özçelik'e, aracın üretimi sırasında sponsorluk anlamında desteklerini esirgemeyen Robotik Otomasyon ve Kontrol Laboratuvarı (rac-lab.com)'na, T3 Vakfına, Kapsül Teknoloji Platformu'na; bu çalışmanın ortaya çıkmasında emeği geçen tüm saygıdeğer hocalarımıza ve personele bizlere verdikleri sonsuz desteklerinden dolayı teşekkürü borç biliriz.

\section{Kaynakça}

Amory, A., \& Maehle, E. (2018). Modelling and CFD simulation of a micro autonomous underwater vehicle SEMBIO. Paper presented at the OCEANS 2018 MTS/IEEE Charleston.

Boehm, J., Berkenpas, E., Henning, B., Rodriguez, M., Shepard, C., \& Turchik, A. (2018). Characterization, modeling, and simulation of an ROV thruster using a six degree-of-freedom load cell. Paper presented at the OCEANS 2018 MTS/IEEE Charleston.

Budiyono, A. (2009). Advances in unmanned underwater vehicles technologies: Modeling, control and guidance perspectives.

Chin, C. S., Lau, M. W. S., Low, E., \& Seet, G. G. L. (2006). Design of thrusters configuration and thrust allocation control for a remotely operated vehicle. Paper presented at the 2006 IEEE Conference on Robotics, Automation and Mechatronics.

Christ, R. D., \& Wernli Sr, R. L. (2013). The ROV manual: a user guide for remotely operated vehicles: ButterworthHeinemann.

Gülgün, T., Alankaya, G., Duran, M. E., Erdoğdu, M., DURDU, A., YALÇINKAYA, İ. s., \& Terzioğlu, H. (2020). Analysis of the Effect on the Thrust Force as a Result of Positioning Thrusters at Different Angles in Underwater Vehicles in CAD Environment. Avrupa Bilim ve Teknoloji Dergisi, 357362.

Gülgün, T., Alankaya, G., Duran, M. E., Erdoğdu, M., Yalçinkaya, İ., Durdu, A., \& Terzioğlu, H. (2020). Low-Cost Unmanned Underwater Vehicle Design. Avrupa Bilim ve Teknoloji Dergisi, 363-367.

Healey, A. J., Rock, S., Cody, S., Miles, D., \& Brown, J. (1995). Toward an improved understanding of thruster dynamics for underwater vehicles. IEEE Journal of Oceanic Engineering, 20(4), 354-361.

Ludvigsen, M., Aasly, K., Ellefmo, S., Zylstra, M., \& Pardey, M. (2017). ROV based drilling for deep sea mining exploration. Paper presented at the OCEANS 2017-Aberdeen.

Muljowidodo, K., Adi N, S., Prayogo, N., \& Budiyono, A. (2009). Design and testing of underwater thruster for SHRIMP ROV-ITB.

Negahdaripour, S., \& Firoozfam, P. (2006). An ROV stereovision system for ship-hull inspection. IEEE Journal of Oceanic Engineering, 31(3), 551-564.

Nian, R., He, B., Yu, J., Bao, Z., \& Wang, Y. (2013). ROV-based underwater vision system for intelligent fish ethology research. International Journal of Advanced Robotic Systems, 10(9), 326.

Tangorra, J. L., Davidson, S. N., Hunter, I. W., Madden, P. G., Lauder, G. V., Dong, H., . . . Mittal, R. (2007). The development of a biologically inspired propulsor for unmanned underwater vehicles. IEEE Journal of Oceanic Engineering, 32(3), 533-550.

Yoerger, D. R., Cooke, J. G., \& Slotine, J.-J. (1990). The influence of thruster dynamics on underwater vehicle behavior and their incorporation into control system design. IEEE Journal of Oceanic Engineering, 15(3), 167-178. 